\title{
DISOCIJACIJA ROMANTIČARSKE SUBJEKTIVNOSI U PESNIŠTVU SIMONA JENKA NA PRIMERU PREVODA MILORADA ŽIVANČEVIĆA
}

Cilj ovog rada je da ukaže na jedan značajan deo prevodilačkog rada prof. dr Milorada Živančevića, koji se odnosi na slovenačku književnost. Na primeru knjige izabrane poezije i proze Simona Jenka Poezija i proza (1975) pokazaćemo koja prevodilačka rešenja je autor primenio prilikom prevođenja Jenkovog stiha, a takođe ćemo se osvrnuti i na proces dezintegracije autorovog romantičarskog subjektivizma $u$ pravcu bidermajera $i$ protorealizma, što je karakteristično i za Branka Radičevića i drugu generaciju srpskih romantičara.

Ključne reči: Simon Jenko, usmena tradicija, prevođenje, romantizam, disocijacija

U bogatom prevodilačkom opusu sa slovenskih jezika, prevodi poezije i proze iz slovenačke književnosti profesora dr Milorada Živančevića zauzimaju posebno mesto (Živančević-Sekeruš, 1989: 249-280). To je utoliko značajnije što je profesor Živančević zajedno sa prof. dr Jožetom Pogačnikom i mr Miroslavom Rankovom sedamdesetih godina prošloga veka osnovao čuvenu ,crvenu ediciju “e, poznatu pod nazivom Slovenačka književnost pri Matici srpskoj, koja je godinama, sve do raspada jugoslovenske države devedesetih godina, bila kanonska u pogledu studijskog, akademskog proučavanja autora i dela ove južnoslovenske književnosti. Tako zamišljen koncept nudio je antologijske i pregledne izbore iz usmene i starije slovenačke književnosti (Začinjavci: reformacija, barok, klasicizam, predromantizam), preko romantičarske poezije i realističke proze, modernista $\mathrm{i}$ najznačajnijih drama i proze Ivana Cankara, međuratnih ekspresionista i avangardista, predstavnika socijalnog realizma, do savremene, izuzetno atraktivne posleratne slovenačke književne scene u svim žanrovima. Izbore i predgovore za ove knjige pisali su najugledniji slovenački književni istoričari, teoretičari i kritičari, a profesor Živančević je od samog početka bio jedan od najagilnijih

\footnotetext{
*bspantovic@ff.uns.ac.rs
} 
prevodilaca kako autora 19. veka (Jenko, Aškerc), koji su mu, s obzirom na užu naučnu oblast, svakako bili veoma bliski, tako i modernista (Kete, Murn, Cankar) i ekspresionističkih pesnika (antologija Franca Zadravca Crveni atom), zatim lirike otpora, proznih dela Cirila Kosmača, itd. Pre nego što se posvetimo Živančevićevom prevodu poezije Simona Jenka i problematici disocijacije romantičarske subjektivnosti koja nas ovde zanima, dužni smo da skrenemo pažnju na još jedan profesorov prevodilački poduhvat.

Miloradu Živančeviću, između ostalog, možemo zahvaliti za prvi integralni, izuzetno uspeo i stilski pregnantan, prevod jednog od najznačajnijih Cankarovih romana Kuća Marije Pomoćnice (1904) u okviru izabrane proze ovog pisca (Proza, 1981, preveli Milorad Živančević i Marija Mitrović). To je osobito značajno ako se ima u vidu da je prvi prevod tog romana iz 1959. godine cenzurisan, te stoga necelovito objavljen zbog erotskih i lascivnih scena, koje se nisu uklapale u tadašnje zvanično socijalističko viđenje i tumačenje Cankara kao naprednog, marksističkog pisca. Profesor Živančević je, naprotiv, možda po prvi put srpskom čitaocu otkrio jednog drugačijeg Cankara, evropskog simbolistu, onog kog je Pol Van Tigem smatrao najznačajnijim srednjoevropskim piscem perioda dekadencije (Pirjevec, 1987: 45).

Ovaj kratki roman (negde preko sto stranica) koji je sam Cankar smatrao svojim najboljim proznim ostvarenjem (Mitrović, 1981: 23), svedoči o složenoj i modernoj narativnoj strukturi dela koje je pisac, inspirisan faktografskim činjenicama, napisao u Beču, kao sasvim originalan spoj naturalističkih i dekadentno-simbolističkih stilskih i poetičkih odlika, inače stalno prisutnih u njegovom delu. Ovaj prevod je srpskoj publici svakako morao delovati znatno drugačije nego prevodi nekih drugih prevodilaca u kojima se nije toliko računa vodilo o višeznačnosti, simboličnosti, alegoričnosti i načelno tropičnosti pojedinih stilema Cankarovog teksta, jer su do izražaja došle i Cankarova poetsko-filozofska, pa i metafizička dimenzija, koje su artikulisane pre svega oko motiva čežnje (hrepenenje). Čežnja je ishodište brojnih proznih i dramskih, muških i ženskih likova, osobito junakinja, kojih u ovom romanu ima ukupno 16. To je kategorija koja je Cankarovom subjektu/likovima imanentna i nije upućena ka nekom drugom objektu, već ih određuje kao subjekte koji čeznu (streme) ka onostranom, transcendentnom, ka unutrašnjoj lepoti i duševnosti koju će upoznati tek u predelima smrti. Građenje ovakve, na momente mistične, atmosfere od prevodioca je iziskivao i izbor određene domaće i evropske tradicije na koju bi se mogao osloniti u približavanju što autentičnijeg doživljaja originala srpskom čitaocu. Zbog toga prevod Cankarove Kuće Marije Pomoćnice ima u sebi nešto i od Rilkeove, 
Zoline, Floberove, Muzilove, ali i lirske proze Isidore Sekulić, pre svega njene muzikalnosti, da bi povremeno podsetio i na srpske moderniste Veljka Milićevića ili Milutina Uskokovića. Naturalistički verizam u prikazivanju ličnih i tragičnih porodičnih odnosa u koje su upletene pomenute devojčice i glavna junakinja Malči, spiritualizovan je i nadograđen simbolističkim vizijama i snažnim poetskim slikama o njihovom drugom životu kao Isusovih izabranica.

Izbor i poezije i proze Simona Jenka $1975 .{ }^{1}$ godine prvi je ozbiljniji i obimniji prevod najznačajnijeg slovenačkog pesnika između Franceta Prešerna i Josipa Murna (Mitrović, 1995: 139). Jenko je bio neka vrsta opozicije Prešernovoj poetici visokog, idealističkog i artistički izuzetno kompleksnog romantizma koji se razvija između 1830. i 1848. godine, dakle znatno ranije nego srpski ili hrvatski romantizam (ilirizam). Ujedno, ovaj pesnik je stvaralački bio odviše snažna ličnost da bi svoju poetiku gradio imitacijom svog velikog prethodnika, već je, kako to tvrdi Boris Paternu, zapravo krenuo u suprotnom smeru od Prešerna i time, za razliku od poezije harmonične forme, zasnovao poeziju tzv. otvorene strukture (Martinović 1986: 46). Boris Paternu to ovako formuliše:

„Napustio je 'klasični' tip evropske poezije, njene zahtevne renesansno artističke forme i njen visoki stil, sve ono što je u Sloveniji majstorski ostvario Prešern. Izabrao je sebi drugo, još nedovoljno potrošeno, premda i ranije načeto ishodište: model jednostavne slovenačke i slovenske narodne pesme, svakako ne kao pesnički etnograf ili eklektik, već kao sasvim samostalan stvaralac. Model „,narodne pesme je subjektivizovao i od njega načinio tip nove lirike, ponekad intelektualističkofilozofske, drugi put lirike raspoloženja, predimpresionističke, treći put proznoopisne, itd. Pri tome je snažno „snizio“ pripovedni stil, oslobodio ga visoke metaforike i retoričke sintakse, podvrgao ga prozaizaciji osećanja i u parodijama otvorio prostor dijalektu, žargonu i varvarizmu........Ukratko, na granici romantizma i realizma Jenko je slovenačku poeziju već oslobodio prema „neklasičnom ${ }^{\text {ee }}$ ili ,antiklasičnom "e pravcu, prethodnici pesničkog modernizmae (Paternu, 1974: 59). ${ }^{2}$

U pesničkom delu Simona Jenka, zasnovanom na lirskoj i lirsko-epskoj usmenoj tradiciji, ukazaćemo na neke postupke koji ga nesumnjivo odvajaju od Prešerna, iako i dalje postoji jaka romantičarska osnova u pojedinim pesmama. Pod uticajem Hajnea i Šopenhauera Jenko u poeziju ali i prozu uvodi humor, ironiju, senzualizam, relativizam, melanholiju i skepticizam, a oni ga ujedno približavaju

\footnotetext{
${ }^{1}$ Simon Jenko, Poezija i proza. Predgovor dr France Bernik: Pesnik između romantike i realizma, prevod dr Milorad Živančević, Matica srpska 1975, Novi Sad, 1975.

${ }^{2}$ Ukoliko nije drugačije naznačeno, prevod je naš.
} 
kulturi i senzibilitetu bidermajera, prisutnog i kod pesnika srpskog romantizma, osobito kod Radičevića i Zmaja, ali i kod Jakova Ignjatovića (Stojanović Pantović, 2011: 50-59).

Bidermajer (nem. Biedermeyer) upućuje na dela iz oblasti književnosti, muzike, vizuelnih umetnosti (posebno arhitekture) i unutrašnjeg dizajna u srednjoj Evropi nemačkog govornog područja u periodu između Bečkog kongresa 1815. i Martovske revolucije 1848. godine, ali se u širem smislu odnosi i na zemlje poput Rumunije, Ukrajine, Poljske ili Srbije (osobito Vojvodine), gde je uticaj Habsburške monarhije bio dominantan (Konstantinović \& Rinner, 2003: 8-10). U idejnom, političkom, socio-kulturnom i estetičkom pogledu predstavlja suprotnost u odnosu na prethodno romantičarsko razdoblje. Termin potiče od pseudonima Gottlieb Biedermeyer, kojim je seoski doktor A. Kusmaul (Adolf Kussmaul) potpisivao svoje satirično-parodične pesme objavljene u listu Münich Fliegende Blätter. Pseudonim je konstruisan od delova dve pesme koje kritikuju apolitičnost i malograđanski (filistarski) duh epohe bidermajera. Tipični pesnici ovog stila/razdoblja jesu Anete Droste-Hilshof (Hülshoff), Eduard Merike (Mörike), Vilhelm Miler (Müller) i Adelbert fon Šamiso (Chamisso). U muzici, najpoznatije su kamerne pesme Franca Šuberta. Kao oznaka za epohu počinje da se koristi početkom 20. veka.

Bidermajer je, prema nekim istraživačima, mnogo više temeljno osećanje sveta i opšta kulturna intencija ili sociokulturna anticipacija nego diferenciran pravac ili pokret (Nemoianu, 1984: 11-12). U sociološkom pogledu njeni konzumenti su predstavnici nove gradske srednje klase u uslovima ubrzane industrijalizacije, ali i mnogo većih političkih pritisaka nego u prethodnom dobu. U tom smislu, tematika književnih dela vezuje se za svakodnevni život i trivijalnosti, za intimizam i porodična osećanja, za nedostatak strasti, mešavinu romantičarskog idealizma i realizma, zadovoljstvo, rezignaciju, karnevalizaciju, satiru i parodiju. U rodovsko-žanrovskom pogledu dominiraju istorijski roman i seoska pripovetka, odnosno pluralizam pesničkih stilova koji donose povlačenje od tzv. zrelog ili visokog romantizma i renovaciju prosvetiteljskih tendencija, kao što je npr. rokoko anakreontika.

Ujedno, u eposi bidermajera dolazi do procvata brojnih ženskih časopisa, dnevnika, magazina, kalendara i do pada visoke estetske paradigme koju je postavio romantizam, kroz procese depatetizacije i snižavanje stila, ironiju, satiru, senzualnost, svest o ljudskoj prolaznosti. To je doba izrazite popularizacije i komercijalizacije romantičarske književnosti sa predznakom masovne kulture (izdaju se Bajke braće Grim 1812-1826, kao i Andersenove Bajke 1846. godine). 
Zbog toga se može reći da književnost i umetnost napuštaju vizionarski, kreativni potencijal u zamenu za disperziju jednog opšteg, empirijskog i praktičnog zadovoljstva i uživanja (Nemoianu, 1984: 9). U periodizaciji moderne nemačke književnosti 19. veka bidermajer se zato određuje između 1815. i 1848. godine - te se o njemu najčešće govori i kao o postromantizmu ili ranom, to jest protorealizmu. U srpskoj komparatistici i nauci o književnosti ovim problematikom se najdoslednije bavio Dragiša Živković (Živković, 1994).

Okolnost da je prevod izbora iz Jenkove poezije i proze (naravno, kvantitativno nužno ograničen, posebno kada je u pitanju pesničko delo) objavljen u pomenutoj ediciji Slovenačka književnost Matice srpske, svedoči i o važnosti ovog prevodilačkog poduhvata i na kulturološko-društvenom planu. Naime, prilikom transfera književnog teksta iz jedne sredine u drugu, i s jednog jezika na drugi, veoma je važna i društvena pozicija toga teksta koju on treba da zauzme u ciljnoj kulturi, ali i društvena pozicija onih koji taj tekst posreduju (prevodioci, kritičari, pisci predgovora, autori izbora i biobibliografskih napomena, izdavačka kuća, itd. (Veselinović, 2014: 57). Upravo zato što su ovi kriterijumi uzeti u obzir kada je reč o strukturi i karakteru edicije (ne ulazeći u pojedinačna prevodilačka rešenja pojedinih tekstova ili celih knjiga), može se reći da je zahvaljujući ciljnoj publici (u ovom slučaju pre svega studentima južnoslovenskih jezika i književnosti, profesorima i široj akademskoj i intelektualnoj javnosti), ona doživela zapaženu i širu recepciju.

Kada je konkretno reč o pesništvu Simona Jenka (1835-1869), on je, za razliku od Franceta Prešerna, srpskoj čitalačkoj publici bio relativno, ako ne i potpuno, nepoznat. Sudeći prema njegovoj vezanosti za usmenu liriku - moglo bi se pretpostaviti da ga je kudikamo lakše prevesti nego artistički složene stalne pesničke oblike iz Prešernovog dela, koji do danas na srpskom jeziku - i dalje teško mogu da prenesu duh originala. Srpski romantizam je, za razliku od slovenačkog, šlegelovskog, čiji su glavni predstavnici bili Matija Čop i France Prešern, bio pod uticajem herderovske, mlađe romantičarske škole, koja se afirmiše u poznom Prešernovom delu posle 1838. godine, a svoj vrhunac nesumnjivo dostiže $u$ poetičkom modelu Simona Jenka, koji je na osoben i kreativan način iskoristio mogućnosti folklorne tradicije. U srpskom romantizmu, pre svega onom vodećem toku pod uticajem Vukovog programa, sonet nije bio rasprostranjen pesnički oblik, jer su se naši romantičari prve i druge generacije uglavnom oslanjali na versifikaciju, formu i stil narodne poezije i u lirici i u epici, a ujedno se pod uticajem evropskih romantičarskih modela od nje i distancirali. Može se reći da je usmena tradicija bila ključna za uspostavljanje kanona srpskog romantizma, 
zauzimajući središnji položaj u konstituisanju njegove celokupne strukture (Ivanić, 2011: 183).

U tom smislu, Jenko je u svojim ključnim pesničkim ciklusima Spomenarke (Obujenke) i Slike (Obrazi) koristio trohejski osmerac katrenske strofe sa isprekidanom rimom i šestosložni katren s ukrštenom rimom, tzv. poljski krakovjak, poznat iz poljske narodne poezije, u kom se uspešno ogledao ilirski pesnik Stanko Vraz u svom kanconijeru Đulabije. Lirski trohejski osmerac u srpskom romantizmu koristili su srpski romantičari u različitim poetskim celinama ili ciklusima, kao što je to Branko Radičević, ali osobito Zmaj i Đura Jakšić, pa zatim u nekim pesmama i Laza Kostić. S druge strane, istaknutom kroatisti i polonisti Miloradu Živančeviću je za prevod ključnog Jenkovog ciklusa Slike od velike pomoći bio upravo Vrazov kanconijer, kao najreprezentativniji primer hrvatskog ilirizma, odnosno romantičarske poezije inspirisane usmenom slovenskom tradicijom. Postoji, međutim, jedna poetičko-stilska okolnost koju je teško iz originala preneti u drugi, makar i veoma srodan, južnoslovenski jezik kakav su srpski ili hrvatski. Simon Jenko je pesnik koji se u formalnom i stilskomotivskom smislu oslanjao na topose, formule, obrasce i stileme usmene lirike i balade, ali ih je ujedno i dekonstruisao, razgrađivao, projektujući u ljubavnu ili deskriptivnu poeziju jedan drugačiji senzibilitet, bitno različit od idealnog Prešernovog romantizma. Njega smo opisali kao postromantičarski, bidermajerski ili protorealistički, jer pre svega napušta jedinstvo i svepovezanost između subjekta i objekta/sveta/prirode, i svedoči upravo o njihovom odvajanju i diskontinuitetu. Subjekt i priroda su posebni, razdvojeni entiteti koji funkcionišu prema vlastitim, međusobno različitim principima. Priroda je večna u odnosu na relativno i ograničeno bivstvovanje pojedinca koji u odnosu prema prirodi zauzima različite vrste odnosa, a ne samo idiličan, kako je to u narodnoj poeziji. Jedan od razloga kritičkog neprihvatanja Jenkove poezije u vreme objavljivanja njegove jedine zbirke za života Pesme (1865) upravo je bilo naglašeno osećanje pesimizma i ironije koji su prožimali naizgled naivne autorove stihove. To je verovatno i razlog (kao npr. u slučaju lirskih pesama Vilijama Blejka) što ih je teško prevesti tako da se iza naizgled prepoznatljive, igrive forme i stila po uzoru na usmenu poeziju zapaze dublja značenjska pomeranja u pravcu modernizacije poetskog postupka i čitalačkog doživljaja, koji nam posreduje ironiju, melanholiju, setu, pesimizam i jetku satiru. To je posebno uočljivo u autorovim patriotskim pesmama, u kojima se ne idealizuje nacionalna prošlost. Naprotiv, kao neko ko živi i stvara u doba Bahovog apsolutizma, Simon Jenko je s puno gorčine svestan beznačajnosti vlastite otadžbine na tadašnjoj geopolitičkoj mapi Evrope. 
Jenkov lirski junak ili junakinja i situacije kroz koje prolaze nemaju auru mističnog zagrobnog sjedinjavanja kao npr. Črtomir i Bogomila u Prešernovom spevu Krštenje na Savici, već su svesni ljubavi kao nečega što je svakodnevno, prolazno i može biti protkano humorom, ironijom, pa čak i crnim humorom. Nasuprot carstvu duha i ideala, kod Jenka caruju čulnost i erotika, nestabilna i nepostojana figura zaljubljenog muškarca koji, doduše, pati za voljenom ženom po rastanku, ali ne pada u zamku iluzije o večnosti takvog odnosa. Naprotiv, jedino što tokom vremena ostavlja trag o njoj upravo jeste sećanje, posle koga dolazi otrežnjenje i svest o nužnoj promeni u životima i žene i muškarca. U pesmi Brza promena (Hitra sprememba) lirski junak opisuje susret bivših ljubavnika i kratko, zapravo trenutno oživljavanje izazvanih emocija:

Meseci proleteli

i mi se opet sreli

oko mi načas sinu,

tvoj pogled nekud minu.

I skoro smeh da plane, odjednom s obe strane, jer shvatismo u trenu kud nam se misli denu. (Jenko, 1975: 69)

Na primeru ove pesme, ali i nekih drugih koje ćemo pomenuti (Pitanje, Za rastanak, Zbogom, Zaboravi, Priča, Spomenarke, Slike), bitno je uočiti Jenkovu izvanrednu sposobnost kratkog, sažetog i efektnog opisa scene koja je simbolična i semantički izuzetno bogata. Preciznim i odsečnim iskazima koje je prevodilac uspeo da dočara srpskom čitaocu, lirski junak prenosi psihološke finese (pogled i skretanje pogleda, zbunjenost, smeh, sećanje, buđenje stare ljubavi na tren) u samo dva katrena, dok u nekim drugim, dužim pesmama lirski junak predstavlja sebe bez trunke idealizma, trezveno, racionalno, zdravorazumski i, rekli bismo, „tipično muškiee:

Bilo bi bolje, devo mila,

za tebe i za mene,

da se zapreta što je bilo, svak svojim putem krene. 
Našto ti ljubav moja nagla meni je igra samo, što ko po nebu laka magla proleće tamo-amo.

Nasumce živim svakog dana, ne pitam šta mi pruža, a ti si željna mirnog stana i brižnog, dobrog muža.

Ne čekaj da se preobratim, u jaram me ne preži, žudiš li da te sreća prati, sa mnom se ti ne veži.

Što mora biti - primi svesno, svak svojim putem kreni, na levo ja, a ti na desno, i prošlost ne spomeni !

(Jenko, 1975: 70)

Jenkov lirski junak nesumnjivo nosi nešto od nestalnog i lakomislenog odnosa prema ženi karakterističnog za bajronistički i onjeginovski tip romantičarskog lika. Za njega je rastanak nešto prirodno i logično, gotovo svakodnevna pojava između dvoje zaljubljenih, a ljubav svedena na igru, nestalnu i prevrtljivu, naglu, neobavezujuću i samim tim kratkotrajnu. Iako se i u Jenkovom najznačajnijem ljubavnom ciklusu Spomenarke, nastalom tokom 1856. i 1857. godine, pojavljuje žal za idealnom, uzvišenom, prešernovskom večnom ljubavlju, naglasak je ipak na psihološkom menjanju, osobito muškarca, a samim tim i prirode te veze koja je osuđena na prolaznost i kraj. U pesmi Za rastanak autor vešto kontrastira suprotne pozicije i osobine žene i muškarca. Dok je njena ljubav postojana, neupitna i ozbiljna, stremeći stabilnosti u privatnom i društvenoinstitucionalnom smislu (brak), dotle je muškarac nestabilan i živi „od danas do

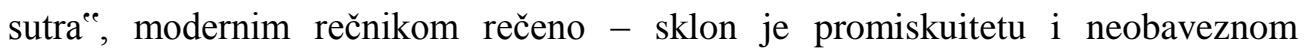
ljubavnom životu. Moglo bi se spekulisati da li je kod njega prisutan strah od vezivanja i „ozbiljnee veze, ali čini se da je za njegov psihološki portret upravo bitna nemogućnost dubljeg emocionalnog vezivanja, koja je karakteristična za postromantičarske i bidermajerske junake. Setimo se samo upečatljive slike mrtve drage Branka Radičevića koja svog voljenog opominje da joj se ne pridružuje u 
zagrobnom životu i da ostane tu gde jeste (Stojanović Pantović, 2011: 59), ili trivijalne i prozaične svakodnevice srpskih studenata u Beču koji sa ženama i mladim devojkama uspostavljaju ,kupoprodajne odnose ${ }^{\text {ee }}$ u njegovom nedovršenom romanu u stihovima Bezimena. Činjenica je da se ovakvim tretmanom erotike, seksualnosti i ljubavi kao trenutnog, vatrenog uzbuđenja koje je prepušteno prolaznosti, veoma blisko modernom osećanju muško-ženskih odnosa, docnijem splinu, dosadi i otuđenosti, koji vode i bračnom neverstvu i bovarizmu (Stojanović Pantović, 2006: 62-65). Ukazaćemo stoga na prvu i poslednju, desetu pesmu iz ciklusa Spomenarke, kojom se zaokružuje Jenkov lirski dnevnik o snazi ljubavi, rastanku, patnji i trezvenom prihvatanju neumitnog protoka vremena i nas samih. Najpre sledi prva, karakteristična pesma, u kojoj je izvanredno dočaran ljubavni i telesni zanos ljubavnika:

\section{Sveća tiho dogorela, dok napolju pljusak teče, udvoje smo posedeli, bilo nam je lepo veče. \\ Slatki osmesi iz oka među suzama se gube, pripija se bok do boka, i usta se čvrsto ljube.}

Nepogoda nebo svali, kiša škropi, voda teče, nas dvoje se milovali, bilo nam je lepo veče. (Jenko, 1975: 57)

Odmah možemo uočiti da je ovo u izvesnom smislu pesma atmosfere i određenog ambijenta, enterijera. Pesma je napisana iz perspektive dvoje, za šta $\mathrm{u}$ slovenačkom jeziku postoji gramatička kategorija dvojine, a u srpskom je nema, pa se prevodi sa mi, dakle množinom, što vodi gubitku autentičnosti, iako je u smisaonom pogledu prihvatljivo. Treći i četvrti stih u prvoj strofi na slovenačkom glase: „skupaj midva sva sedela, / nama lep večer je bil (Jenko, 1961: 16), isto kao i u pretposlednjem i poslednjem stihu završnog katrena: ,midva pa sva se ljubila, / lep večer je nama bil ${ }^{e e}$. Upotreba dvojine svakako kod slovenačkog čitaoca (u većoj meri nego kod srpskog) izaziva utisak intimnosti i muško-ženske bliskosti, što je 
pesniku i bio cilj. Takođe, ponavljanjem stiha bilo nam je lepo veče postiže se izrazitija muzikalnost stiha, koji u originalu prate i niz asonanci, aliteracija $\mathrm{i}$ dosledno ženska rima. Ujedno se naglašava razlika između strasti dvoje zaljubljenih koji ne obraćaju pažnju na siloviti pljusak i nepogodu koja vitla napolju, izvan njihovog zaštićenog prostora $\mathrm{u}$ kom provode poslednje trenutke pred neizbežni rastanak. Slika sveće koja tiho dogoreva asocira na Prešernov motiv iz Soneta nesreće, a posebno se poslednja pesma može dovesti u vezu sa Prešernovim završnim sonetom Memento mori:
Vreme kruži neprestano
leči rane, nove stvara, samo moja svakim danom otvara se rana stara.
S godinama, tokom mena, mi ćemo se izmeniti - ti ćeš jednom umna žena, a ja muž ću dobar biti.

Srce će već malaksati, san nestati kao pena; ništa neće preostati, samo suzna uspomena. (Jenko, 1975: 66)

Slika cikličnog vremena jeste nešto što Jenka nesumnjivo povezuje i sa njegovim naslednikom, modernistom Josipom Murnom, koji je prirodu takođe koristio kao medijum najrazličitijih osećanja i dramatizacije stanja lirskog subjekta, baš kao i naš pesnik u ciklusu od 20 kratkih pesama Slike. U Jenkovom slučaju, bolna, ali trezvena konstatacija da u lirskom junaku postoji rana koja ne da zaceliti, ali da uprkos tome - sve ide svojim tokom promena - i on, i žena, i njihovi životi u budućnosti, i čitav svet, jeste nešto što se bitno razlikuje od Prešernovog tragičnog doživljaja jedinke u pomenutom sonetu. Za Prešerna je ,život zatvor, vreme krvnik hudie ${ }^{\text {,e }}$ i jedino što nam preostaje jeste da osluškujemo kada će smrt doći po nas, kao i po ostale, jer u smrti smo svi jednaki. Svaki veličanstveni napor pojedinca osuđen je na propast, a ljubav je samo tren i iluzija, bez nade na ostvarenje, i Prešern neprestano opominje čitaoca da je život beznadežno prolazan. Kod Jenka je prolaznost samorazumljiva i pesnik je ne doživljava tragično i rezignirano, već 
melanholnično i s blagim osećanjem (samo)ironije. Ljudski život ima svoje uzlete, ali i faze opadanja kada će osećanja neizostavno oslabiti, zamreti, a snovi iz mladosti nestati poput pene. U sedmoj pesmi ciklusa o prirodi Slike, Jenko će iskoristiti poznati (pred)romantičarski motiv ruševina (ruina) da bi simbolizovao meditaciju i pitanje o suštini života. Bitan je momenat kada mu na pitanje o smislu života ne odgovara razvalina, već se sam eho koncentriše oko materijalnosti zvuka, gotovo simbolistički nerazumljivog, tajanstvenog govora koji se artikuliše tek u odjeku (Juvan, 2010: 542).

Inače je za Jenkov poetski postupak karakterističan ne samo precizan opis koji vodi prozaizaciji i depatetizaciji iskaza već i uvođenje monološke i dijaloške forme koja dodatno dramatizuje tekst, osobito u ciklusima Spomenarke i Slike. Posebno je značajno formalno stavljanje znakova navoda prilikom govora određenih poetskih subjekata/instanci, npr. žene/drage, pojedinih motiva iz usmene tradicije, kakvi su mesec, sunce, ruža, ptica, junak na konju, lipa, itd., čime se ujedno objektivizuje njihov govor $\mathrm{i}$ distancira od ja ispovedne forme, a $\mathrm{s}$ druge strane uvodi izvesna ironijska dimenzija u naoko lirski iskaz. Ovakav tip hajneovske ironije koja ima $\mathrm{i}$ crnohumorne, pa $\mathrm{i}$ apsurdne akcente nije karakterističan u toj meri za srpske ili hrvatske romantičare, izuzev za neke pesme Branka Radičevića, Đure Jakšića ili kasnije Laze Kostića. Zbog toga može, uprkos vernom prevodu na naš jezik, doći do izvesnog recepcijskog šuma, pa i nedovoljnog razumevanja Jenkove poezije i njene, ,neobaveznostice, lakoće, na prvi pogled. Ukoliko se pak uporede i Živančevićevi prevodi Jenkovih karakternih novela Tilka i Jeprški učitelj u istom izdanju, čitalac će imati jasniju sliku na kom tradicijskom fonu može da razume jedinstvenu poetiku Simona Jenka, koja je povezana i sa recepcijom Gogoljevog dela u slovenačkoj književnosti (Stojanović Pantović, 1995: 51-53).

Bojana S. Stojanović Pantović

\section{DISSOCIATION OF THE ROMANTIC SUBJECTIVITY IN THE POETRY OF SIMON JENKO BASED ON TRANSLATIONS OF MILORAD ŽIVANČEVIĆ}

\section{Summary}

In this paper we analyse poetic cycles and poems of a post-romanticist Slovenian poet Simon Jenko (1835-1869) translated from the Slovenian into Serbian by dr. Milorad Živančević. As the founder and editor of the special edition Slovenian Literature in Matica srpska, professor Živančević published Jenko's collection Poetry and Prose in 1975 with an introduction of dr. France Bernik. This edition has gained a wide reception both in academic 
and scholar community and in the readership of the former Yugoslavia. The concept of the edition aimed to represent canonical authors of the Slovenian literature from Protestant Reformation to the contemporary literary scene.

Regarding the poetry of Simon Jenko we discusse types of his verse, form and style that is rooted in the oral tradition of the Slovenian poetry but is also comparable to the Serbian Romantic poets Branko Radičević, J. J. Zmaj, Djura Jakšić and partly Laza Kostić, whish the translator also had in his mind. The apparent simplicity and ease of Jenko's verse can be misleaded by the Serbian readers because he uses topoi and formulas of the oral poetry in a subversive way, anticipating quite opposite meaning than artistically demanding Romanticism of France Prešeren. In Jenko's lyrics love has been presented as a current and short-lived, more as a daily experience of a subject that leads to disintegration and dissociation of Romantic eternal, idealistic love, approaching to Biedermeyer and early Realism on the one hand, and Impressionism on the other.

Keywords: Simon Jenko, oral tradition, translation, desintegration of Romanticism

\section{IZVORI}

Jenko, S. (1961). Izbrano delo. Ljubljana: Mladinska knjiga.

Jenko, S. (1975). Poezija i proza. Preveo Dr Milorad Živančević. Novi Sad: Matica srpska.

\section{LITERATURA}

Veselinović, S. (2013). Prevođenje, recepcija i kanon. Aspekti identiteta i njihovo oblikovanje u srpskoj književnosti. Gorana Raičević (prir.). Novi Sad: Filozofski fakultet, 55-63.

Živančević-Sekeruš, I. (1989). Bibliografija dr Milorada Živančevića. Zbornik za slavistiku, 37, 249-280.

Živković, D. (1994). Evropski okviri srpske književnosti, knj. I. Beograd: Prosveta.

Ivanić, D. (2011). Ka genezi srpske poezije. Beograd: Licej.

Juvan, M. (2010). The palimpsest of ruins: cultural memory, European literary intertext, and post-romanticism in Simon Jenko's "Picture VII". Neohelicon, 37, 537-543.

Konstantinović, Z., \& Rinner, F. (2003). Eine Literaturgeschichte Mitteleuropas. Insbruck: Studien.

Mitrović, M. (1981). Deklarativnost i višeznačnost u delu Ivana Cankara. U: Ivan Cankar. Proza. Novi Sad: Matica srpska, 9-38.

Mitrović, M. (1995). Pregled slovenačke književnosti. Novi Sad-Sremski Karlovci: Izdavačka knjižarnica Zorana Stojanovića. 
Nemoianu, V. (1984). The Taming of Romanticism. European Literature and the Age of Biedermeyer. Harward University Press.

Paternu, B. (1974). Pogledi na slovensko književnost, knj. I. Ljubljana: Mladinska knjiga, 47-76.

Stojanović Pantović, B. (1995). Linija dodira. Gornji Milanovac: Dečje novine, 4863.

Stojanović Pantović, B. (2006). Pobuna protiv središta. Pančevo: Mali Nemo, 9197.

Stojanović Pantović, B. (2011). Rasponi modernizma. Novi Sad: Akademska knjiga, 50-59. 